\title{
The role of convective overshooting clouds in tropical stratosphere-troposphere dynamical coupling
}

\author{
K. Kodera ${ }^{1,2}$, B. M. Funatsu ${ }^{3,4}$, C. Claud ${ }^{4}$, and N. Eguchi ${ }^{5}$ \\ ${ }^{1}$ Solar-Terrestrial Environment Laboratory, Nagoya University, Nagoya, Japan \\ ${ }^{2}$ Climate and Ecosystems Dynamics Division, Mie University, Tsu, Japan \\ ${ }^{3}$ LETG-Rennes COSTEL, Université Rennes 2, Rennes, France \\ ${ }^{4}$ Laboratoire de Météorologie Dynamique/IPSL, CNRS, Ecole Polytechnique, Palaiseau, France \\ ${ }^{5}$ Research Institute for Applied Mechanics, Kyushu University, Kasuga, Japan \\ Correspondence to: K. Kodera (kodera@stelab.nagoya-u.ac.jp)
}

Received: 26 August 2014 - Published in Atmos. Chem. Phys. Discuss.: 15 September 2014

Revised: 25 May 2015 - Accepted: 2 June 2015 - Published: 18 June 2015

\begin{abstract}
This paper investigates the role of deep convection and overshooting convective clouds in stratospheretroposphere dynamical coupling in the tropics during two large major stratospheric sudden warming events in January 2009 and January 2010. During both events, convective activity and precipitation increased in the equatorial Southern Hemisphere as a result of a strengthening of the BrewerDobson circulation induced by enhanced stratospheric planetary wave activity. Correlation coefficients between variables related to the convective activity and the vertical velocity were calculated to identify the processes connecting stratospheric variability to the troposphere. Convective overshooting clouds showed a direct relationship to lower stratospheric upwelling at around $70-50 \mathrm{hPa}$. As the tropospheric circulation change lags behind that of the stratosphere, outgoing longwave radiation shows almost no simultaneous correlation with the stratospheric upwelling. This result suggests that the stratospheric circulation change first penetrates into the troposphere through the modulation of deep convective activity.
\end{abstract}

\section{Introduction}

Weather forecasting in tropical regions is challenging due to the unstable nature of the atmosphere there and its sensitivity to various extratropical disturbances. The impact of the extratropical circulation on the tropics, such as the lateral propagation of tropospheric Rossby waves, has been stud- ied previously (e.g. Kiladis and Weickmann, 1992; Funatsu and Waugh, 2008). The influence from above (i.e. from the stratosphere) is generally neglected, but under certain circumstances, such as during a sudden stratospheric warming (SSW) event, stratospheric meridional circulation change can modify convective activity as will be shown later.

Early satellite measurements showed that enhanced poleward eddy heat fluxes in the extratropical stratosphere induce tropical cooling through changes in the mean meridional circulation (Fritz and Soules, 1970; Plumb and Eluszkiewicz, 1999; Randel et al., 2002). It is generally believed that such changes in the stratosphere do not affect the troposphere, due to the difference in air density between the two. Indeed, tropical temperature change induced by the intraseasonal mean meridional circulation is apparent only in the layer around $70 \mathrm{hPa}$ and above (Ueyama et al., 2013).

However, this does not imply that the stratospheric meridional circulation has no impact on the atmosphere below the $70 \mathrm{hPa}$ level. A possible impact of stratospheric meridional circulation on cumulus heating has been suggested by Thuburn and Craig (2000) in a simplified general circulation model experiment. Stratospheric upwelling effects on tropical convection is also confirmed by a more realistic general circulation model forecast study (Kodera et al., 2011a). These models make use of cumulus parameterization to account for the effect of convection into large-scale circulation. Therefore, model sensitivity should be dependent on the parameterization used. 
Stratospheric effect on tropical convection is also found in non-hydrostatic models that treat the convection explicitly. Although it is not fully understood yet how stability near the tropopause influences anvil cloud-top height, Chae and Sherwood (2010) showed with observational data and a regional non-hydrostatic model experiment that the variation of static stability near the tropopause due to a change in the stratospheric upwelling, influences cloud height even if the cloud height peaks only near $12 \mathrm{~km}$ (or $200 \mathrm{hPa}$ ). Using a global non-hydrostatic model simulation, Eguchi et al. (2015) also found that increased tropical upwelling due to a SSW event reduces the static stability in the upper tropical tropopause layer (TTL), which leads to an increase of deep convective activity in the troposphere.

Temperature response to stratospheric upwelling becomes unclear in the region lower than the tropopause because clouds form in response to adiabatic cooling associated with upwelling. Stratospheric temperature decreases, but minimal temperature changes occur in the TTL, resulting in a decrease in static stability in the upper TTL (Li and Thompson, 2013). In the regions where deep convective clouds are frequent, stratospheric influence further penetrates deeper in the troposphere (Eguchi and Kodera, 2010; Kodera et al., 2011b). Once the distribution of convective clouds is modified, this effect can be amplified within the troposphere through a feedback involving water vapour transport (Eguchi and Kodera, 2007).

In a previous study composite analysis of the tropical tropospheric impact of SSW events were made for the winters from 1979 to 2001 (Kodera, 2006). Even though significant responses were found in the tropical troposphere, a problem of the composite analysis is that, by averaging many different events to extract a common feature, detailed structures often become obscure. Therefore, case studies are made in the present paper on two exceptionally large events focusing on the role of overshooting and deep convective clouds in stratosphere-troposphere dynamical coupling in the tropics. The selected two largest SSW events of January 2009 and January 2010 (Harada et al., 2010; Ayarzagüena et al., 2011) have a large impact on the tropical upwelling in the lower stratosphere as will be shown later. These SSWs are not only large but also localized in time unlike other SSWs. Large and simple structure of the temporal variation of the forcing (eddy heat flux) and the response (stratospheric zonal wind) of 2009 and 2010 SSWs permit us to investigate a detailed feature of the circulation change. It should also be noted that not all major SSW events necessarily have such large tropical impacts, as this depends on the latitude of the associated planetary wave breaking (Taguchi, 2011).

\section{Data}

Meteorological reanalysis data from the European Centre for Medium-Range Forecasts (ECMWF) ERA interim (Dee et al., 2011) were used to analyse air temperature and winds including vertical velocity. Cloud data in the TTL, from the Level 2 Cloud Layer Product (Version3-01), were obtained by Cloud-Aerosol LIdar with Orthogonal Polarization (CALIOP) aboard the CALIPSO satellite (Winker et al., 2007). Outgoing longwave radiation (OLR) data provided by NOAA (e.g. Arkin and Ardanuy, 1989) is widely used to analyse convective activity in the tropics. In this study, in addition to the OLR data with a $2.5^{\circ} \times 2.5^{\circ}$ lat-lon resolution, we used the Microwave Humidity Sensor (MHS) channels 3 to 5 to detect deep convection and convective overshoots because of the scattering by icy particles in precipitating clouds so cold that they cause a depression in the brightness temperatures. MHS data are obtained from NOAA18 and MetOp-A. The equatorial crossing time for these platforms is approximately 14:00 local time (LT) for NOAA18, and 21:30 LT for MetOp-A. In the present work, the original data were regridded to a regular grid with resolution of 0.25 lat $\times 0.25$ lon. The figures show DC and COV occurrences resampled to a grid of $2.25 \times 2.25$ for plotting purposes.

To capture deep, precipitating clouds we used the diagnostics developed for the tropics by Hong et al. (2005), which is based on the brightness temperature differences $(\Delta T)$ measured by three channels of the MHS between (i) $183.3 \pm 1$ and $183.3 \pm 7 \mathrm{GHz}(\Delta T 17$ ); (ii) $183.3 \pm 1$ and $183.3 \pm 3 \mathrm{GHz}(\Delta T 13)$; and (iii) $183.3 \pm 3$ and $183.3 \pm 7 \mathrm{GHz}(\Delta T 37)$. Deep convective cloud (DC) and convective overshooting (COV) were discriminated according to the following criteria, in which COV refers to clouds able to penetrate into the tropopause region (Hong et al., 2005; Funatsu et al., 2012): deep convective cloud: $\Delta T 17 \geq 0, \Delta T 13 \geq 0$, and $\Delta T 37 \geq 0 \mathrm{~K}$; convective overshooting: $\Delta T 17 \geq \Delta T 13 \geq \Delta T 37>0 \mathrm{~K}$.

Although these high frequencies are generally not sensitive to cirrus and anvil cirrus clouds, they will probably have difficulty distinguishing some strong anvil clouds from deep convective clouds. But fortunately, these strong anvil clouds are generally tightly connected with deep convective cloud systems (Hong et al., 2008).

The Tropical Rainfall Measuring Mission (TRMM) dailyintegrated precipitation (TRMM 3B42 v7) was used to study surface precipitation (Huffman et al., 2007).

\section{Results}

An enhanced Brewer-Dobson (BD) circulation during a stratospheric warming event creates strong downwelling in the polar region and upwelling in the tropical stratosphere, and thus a warming and cooling tendency in these respective regions. Figure 1a and $\mathrm{b}$ show the evolution of eddy heat flux at $100 \mathrm{hPa}$ averaged over the extratropical Northern Hemisphere $\left(\mathrm{NH} ; 45-75^{\circ} \mathrm{N}\right)$, and the latitude-time section of the zonal mean pressure coordinate vertical velocity at $50 \mathrm{hPa}$ from 01 January to 11 February (the left and right panels are 

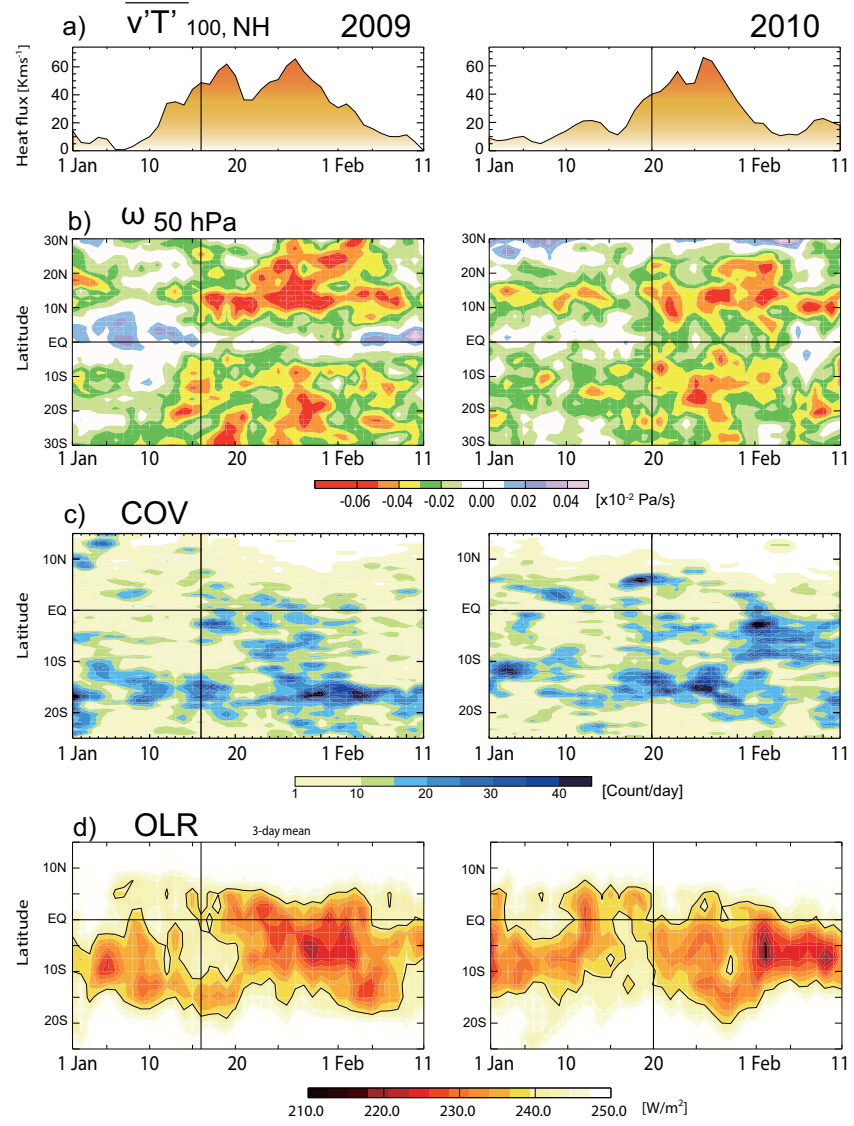

Figure 1. (a) Time series of the eddy heat flux at $100 \mathrm{hPa}$ averaged over $45-75^{\circ} \mathrm{N}\left(\mathrm{K} \mathrm{m} \mathrm{s}^{-1}\right)$. (b) Zonal mean pressure coordinate vertical velocity at $50 \mathrm{hPa}\left(\mathrm{Pa} \mathrm{s}^{-1}\right)$. (c) Number of convective overshootings per day at each latitude. (d) Zonal mean OLR $\left(\mathrm{W} \mathrm{m}^{-2}\right)$. Variables are displayed from 1 January to 11 February. Left- and right-hand panels are for 2009 and 2010, respectively. Vertical velocity and OLR data are smoothed by a 3-day running mean.

for 2009 and 2010, respectively). In both years, stratospheric upwelling in the tropics at the $50 \mathrm{hPa}$ level strengthens following the increase in wave activity at around 16 January 2009 and around 20 January 2010 (indicated by the solid vertical lines in the figure). In the tropics, an increase in COV is synchronous with the stratospheric upwelling (Fig. 1c). The convective activity represented by the OLR also increases in the Southern Hemisphere (SH), which can also be characterized as a southward shift of the active convective region (Fig. 1d). A delay in the response of the OLR in the SH is also noted. The difference in the characteristics in the temporal variation in COV and OLR relative to the vertical velocity at $50 \mathrm{hPa}$ becomes also apparent in the vertical structure of the correlation coefficient in the following.

To study the relationship between tropospheric convective activity and the vertical velocity at different pressure levels, correlation coefficients were calculated between variables representing a convective activity (COV, DC, and OLR)

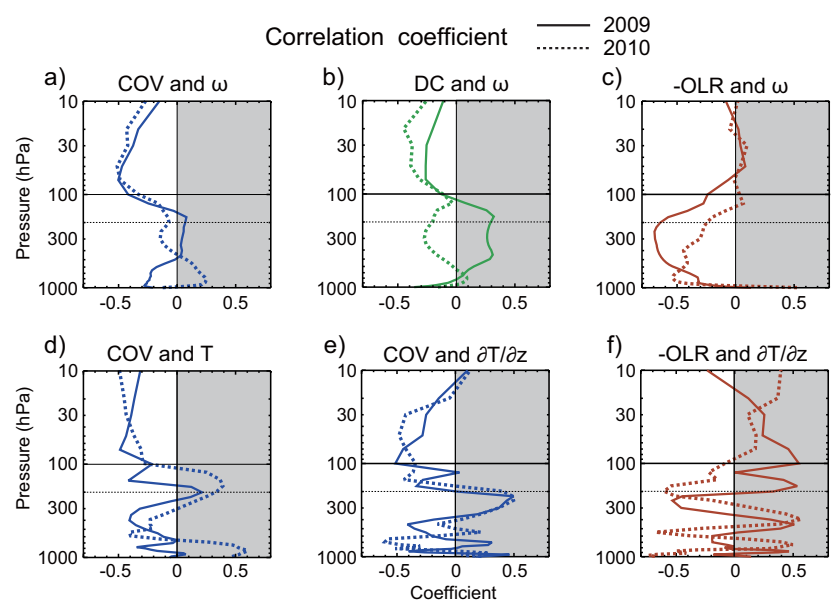

Figure 2. (a) Correlation coefficient between the pressure coordinate vertical velocity $(\omega)$ at each pressure level and the daily convective overshooting occurrence frequency (COV) averaged over the tropics. (b) As for panel (a) but for deep convection (DC). (c) As for (a) but for the correlation coefficient with -OLR. (d) Same as in panel (a) except for COV and temperature at each level. (e) Same as in panel (d) except for COV and vertical temperature gradient at each level. (f) Same as in panel (e) except for -OLR and vertical temperature gradient. Variables were first averaged over $25^{\circ} \mathrm{S}$ to $25^{\circ} \mathrm{N}$, and then the correlation was calculated over 31 days centred at the onset day (16 January in 2009 and 20 January in 2010). Solid and dashed lines indicate 2009 and 2010, respectively.

and the pressure vertical velocity $(\omega)$ at each level (Fig. 2). These correlation coefficients are simply being used to identify the relation between dynamical variables in two rather short-duration events. Variables were first averaged over the tropics $\left(25^{\circ} \mathrm{S}\right.$ to $\left.25^{\circ} \mathrm{N}\right)$, and then correlations were calculated for the 31-day period centred on the onset day (16 January for 2009 and 20 January for 2010). For convenience of comparison, the sign of the OLR was reversed (-OLR). In both winters, $\mathrm{COV}$ shows the highest correlation, with $\omega$ in the lower stratosphere around $70-50 \mathrm{hPa}$. DC is also correlated with the stratospheric upwelling, but less so. The OLR shows little relationship with the stratospheric circulation, although it is correlated with vertical velocity in the upper troposphere.

Here, we check the physical consistency among the variables by comparing the correlation coefficients among them. It is reasonable to expect that stratospheric vertical velocity should have the strongest relationship with the occurrence of COV (i.e. convection penetrating to the stratosphere) and the weakest relationship with OLR, which is sensitive to lower clouds as well as deep convection. Therefore, the following inequalities among the correlation coefficient, $r$, between the lower stratospheric pressure vertical velocity, $\omega$, should be expected: 


$$
\begin{gathered}
r_{\omega, \mathrm{COV}}<0, \quad\left|r_{\omega, \mathrm{COV}}\right|>\left|r_{\omega, \mathrm{DC}}\right| \\
\left|r_{\omega, \mathrm{DC}}\right|>\left|r_{\omega,-\mathrm{OLR}}\right|
\end{gathered}
$$

where $r_{\omega, \mathrm{COV}}, r_{\omega, \mathrm{DC}}$, and $r_{\omega,-\mathrm{OLR}}$ are the correlation coefficients between $\omega$ and COV, DC, and -OLR, respectively.

This relationship is satisfied in the correlation analysis presented in Fig. 2. This result supports our working hypothesis that lower stratospheric vertical velocity variation is coupled with the tropical convective activity.

The present study can also be compared with a regression study of the BD circulation index by Li and Thompson (2013); enhanced BD circulation increases clouds occurrence above the tropical tropopause, in association with a decrease of stratospheric temperature and the static stability around the tropopause. The structure of the tropical temperature and stability change associated with the COV is consistent with a variation associated with a strengthening of the BD circulation. Formation of the clouds above the tropopause is also consistent with the correlation of COV with upwelling above $100 \mathrm{hPa}$.

Figure 3 depicts a development of downward coupling in the equatorial summer tropics, averaged between $20^{\circ} \mathrm{S}$ and the Equator. The temperature tendency (Fig. 3a) shows a rapid decrease in the stratosphere following the increase in the eddy heat flux in Fig. 2a, but no clear temperature signal is observed in the troposphere, which agrees with the results of a previous study (Ueyama et al., 2013). Figure 3b shows the altitude-time section of measured cloud frequency (optical thickness < 4) by CALIOP. Horizontal dashed lines indicate approximate height corresponding to $100 \mathrm{hPa}$ pressure level (solid lines in Fig. 3a and c). Prior to the SSWs, thin clouds are formed near $16.6 \mathrm{~km}$ (or $100 \mathrm{hPa}$ ) around a cold point tropopause. When cooling events start, clouds form at all levels from the upper to the lower TTL, indicating a development of convective activity. Pressure vertical velocity is shown as a departure from the period mean normalized by a daily standard deviation at each level to visualize the large range of variation (Fig. 3c). Although vertical velocity varies in a similar manner to temperature tendency in the stratosphere, an increase in the upwelling also occurs in the troposphere following the stratospheric change. This tropospheric upwelling is associated with an increase in surface precipitation (Fig. 3d).

This result shows that the temperature tendency is a good proxy for vertical velocity in the stratosphere. However, dynamical cooling tends to be compensated by diabatic heating due to cloud formation lower than the tropopause as illustrated in Fig. 3; consequently, the temperature tendency is no longer a good indicator of the vertical velocity below $70 \mathrm{hPa}$.

Figure 4 shows the evolution of the geographical distribution of OLR and COV before (i) and after (ii) the onset of the event. The influence of the El Niño-Southern Oscillation (ENSO) is evident in the OLR during period (i). In Jan-
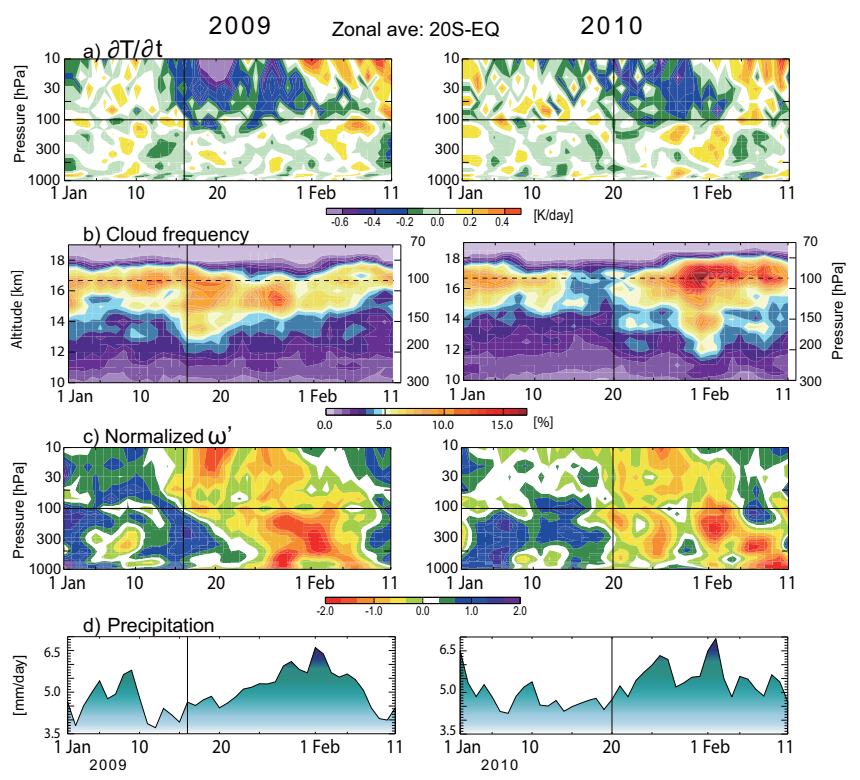

Figure 3. (a) Similar to Fig. 1 except for the pressure-time section of the zonal mean temperature tendency averaged over the SH tropics $\left(20^{\circ} \mathrm{S}\right.$ to the Equator) $\left(\mathrm{K} \mathrm{day}^{-1}\right)$. (b) As for panel (a) except for the geographical altitude-time section of cloud frequency measured by CALIOP (\%). (c) As for panel (a) except for the pressure coordinate vertical velocity anomalies normalized by the standard deviation of daily variability. (d) Time series of the daily TRMM surface precipitation averaged over $\mathrm{SH}$ tropics $\left(\mathrm{mm} \mathrm{day}^{-1}\right)$. Horizontal solid lines in panels (a) and (c) and dashed lines in panel (b) indicate $100 \mathrm{hPa}$ pressure level.

uary 2009, which is a cold phase of ENSO, a well-developed region of low OLR is located over the Maritime Continent, while in January 2010, a warm phase of ENSO, it is located over the western Pacific according to the change in the equatorial Pacific sea surface temperature (SST). The velocity potential at $925 \mathrm{hPa}$ (contour lines) in period (i) indicates that these convective activities are maintained by a large-scale low-level convergence. After the onset of the stratospheric event during period (ii), the low-OLR centre over the Maritime Continent or western Pacific is weakened, and multiple convective-active regions develop in the $\mathrm{SH}$ along $15^{\circ} \mathrm{S}$. This active convective zone includes tropical cyclones and storms (names are indicated below the panel) over warm ocean sectors near Madagascar, north of Australia, and in the southwestern Pacific.

The occurrence of COV is high over the African and South American continents, but no particular enhancement is seen around the Maritime Continent-western Pacific region in period (i). This indicates the weaker dependency of COV on low-level convergence. Although the occurrence of COV increases after the onset in period (ii), no substantial change is seen in the spatial structure except that the COV distribution takes a more zonal form. The distribution of the regions with low OLR becomes increasingly similar to that of COV 

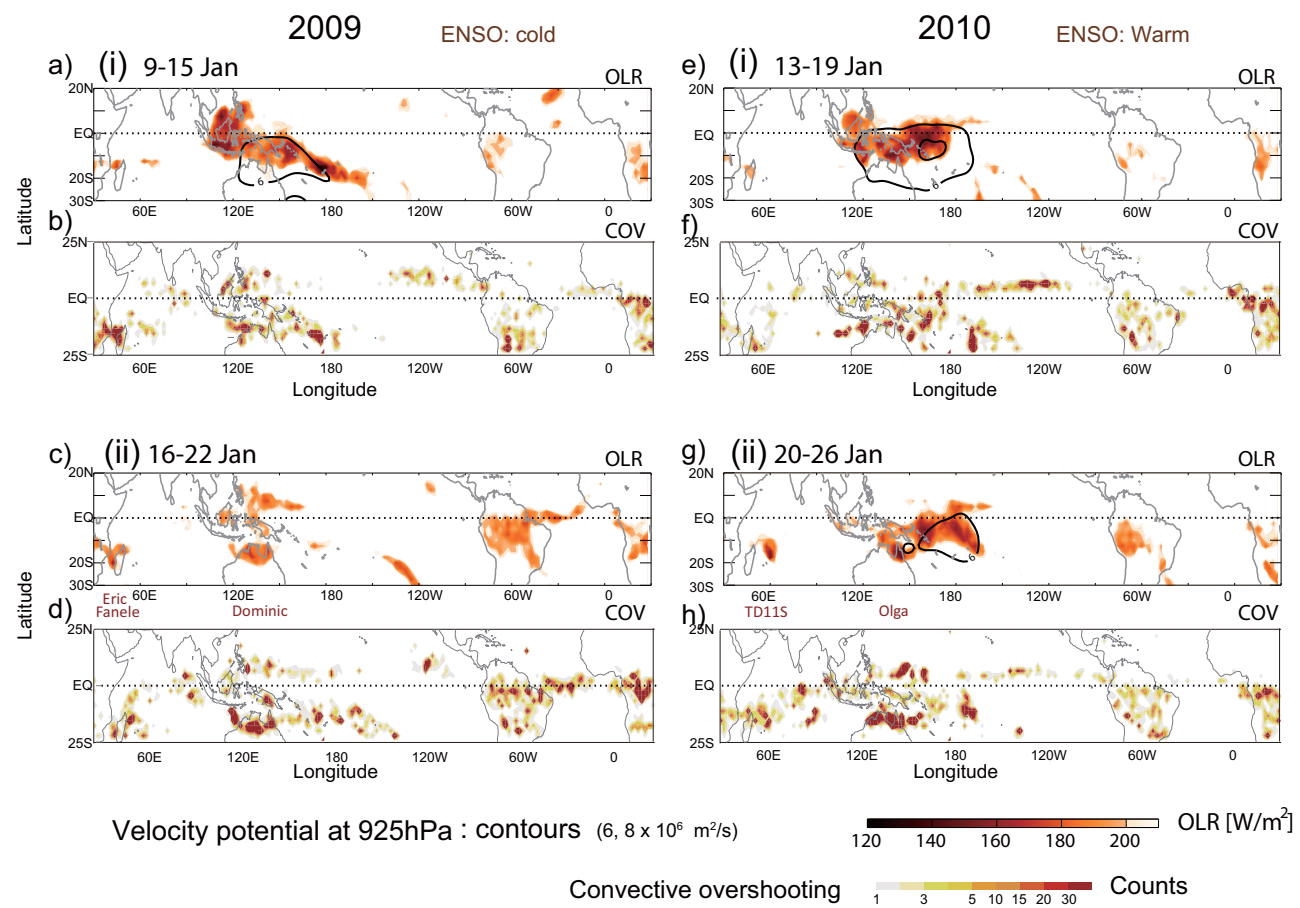

Figure 4. (a, c, e, g) Seven-day mean OLR (color shadings) with velocity potential at $925 \mathrm{hPa}$ (contours of 6 , and $8 \times 10^{6} \mathrm{~m}^{2} \mathrm{~s}{ }^{-1}$ ). (b, d, f, h) Seven-day average of the number of COV in each $2.5^{\circ}$ lat-lon grid box. Panels (a, b) and (c, d) are 7-day periods before (i) and after (ii) the onset of the event in January 2009. Panels $(\mathbf{e}, \mathbf{f})$ and $(\mathbf{g}, \mathbf{h})$ are the same as panels $(\mathbf{a}, \mathbf{b})$ and $(\mathbf{c}, \mathbf{d})$ except for the event in January 2010.

during period (ii). This indicates that the COV-related deep convective activity becomes important after the onset of the stratospheric event.

\section{Summary and discussion}

The results of our analysis of changes in tropical circulation associated with large SSWs during January 2009 and January 2010 can be summarized as follows.

Enhanced stratospheric wave activity produced a cooling in the tropical stratosphere through a strengthening of the BD circulation. This influence penetrated downward into the troposphere through a change in the cloud formation. Among the variables representing different convective activity, COV shows the highest correlation with the lower stratospheric vertical velocity. This result is reasonable because the COV clouds penetrate above the tropopause and interact directly with the stratospheric circulation. The reason for low correlation of the OLR with stratospheric upwelling originates from the fact that the tropospheric variation lags by about a week (Fig. 1).

The results obtained from the present two SSW events are consistent with the earlier results from an independent composite analysis of the $\mathrm{NH}$ winters for the period of 1979 to 2001. Figure 5a shows the results of the above-mentioned composite analysis. Twelve SSW events of which maximum deceleration of the polar night jet (average $50-70^{\circ} \mathrm{N}$ ) at
$10 \mathrm{hPa}$ exceeds $2 \mathrm{~m} \mathrm{~s}^{-1}$ day $^{-1}$ with a smoothed data are selected (see detail in Kodera, 2006). The key day is defined as the day of the largest deceleration. Student $t$ values corresponding to a $95 \%$ significance level for one- and two-sided tests are 1.8 and 2.2, respectively. Following a deceleration of the polar night jet, statistically significant increase in the upwelling occurs in the tropical stratosphere around day 2 , and in the tropospheric equatorial SH around day 4 to 11 .

Two SSW events in the present study are juxtaposed below in Fig. 5b. The top panel shows the zonal-mean zonal wind tendency of winters 2009 and 2010 similar to the top panel of Fig. 5a. The tropical vertical pressure velocity in the $\mathrm{SH}\left(20^{\circ} \mathrm{S}-\mathrm{Eq}\right)$ is presented in a similar way to the composite analysis by choosing the day of the maximum deceleration as the time origin. We can see that the upwelling in the tropical SH increases in the upper troposphere around day 4 to day 11 similarly to the composite mean (rectangles in Fig. 5). Therefore the relationship that we have identified here in two particularly strong SSWs between the SSW and the enhancement of tropical convection is consistent with that previously identified from the composite analysis.

To get an insight into a possible mechanism of connection between the stratospheric and tropospheric variability, we also calculated correlations between the temperature or vertical temperature gradient (or static stability) at each level and COV or -OLR (Fig. 2 bottom). COV shows a stronger relationship around the tropopause with vertical temperature gra- 
a) Composite analysis of 12 SSWs
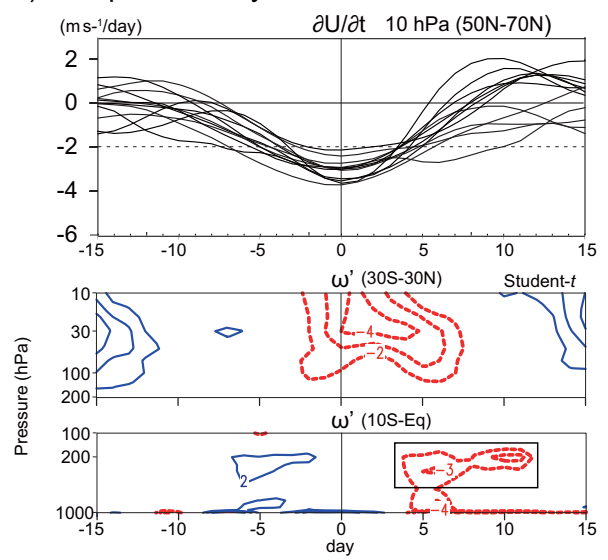

b) $2009,2010 \mathrm{SSWs}$
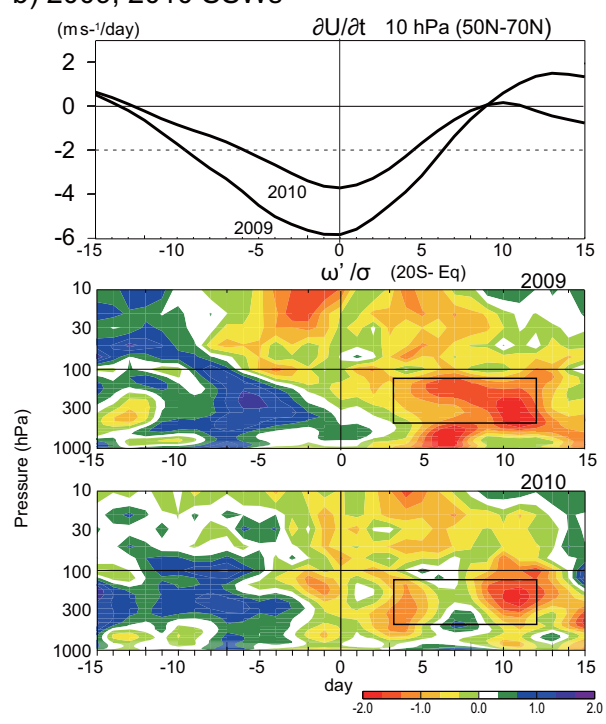

Figure 5. (a) Composite analysis of 12 SSWs during boreal winters from 1979 to 2001 (see Kodera, 2006, for detail): low-pass-filtered zonal-mean zonal wind tendency at $10 \mathrm{hPa}$ averaged over $50-70^{\circ} \mathrm{N}$ of 12 events (top). Student $t$ values of composited vertical pressure velocity averaged over $30^{\circ} \mathrm{S}-30^{\circ} \mathrm{N}$ in the stratosphere (middle) and those of $10^{\circ} \mathrm{S}$-Equator in the troposphere. (b) Zonal-mean zonal wind tendency in winters 2009 and 2010 similar to top panel in (a). Normalized tropical vertical pressure velocity averaged over $20^{\circ} \mathrm{S}-$ Equator in January 2009 (middle) and January 2010 (bottom). Vertical lines indicate key date (see text). Rectangles indicate a period of enhanced tropospheric upwelling in panel (a).

dient (Fig. 2e) than temperature itself (Fig. 2d). This means that $\mathrm{COV}$ is sensitive to the stability around the tropopause region $(100 \mathrm{hPa})$, while OLR is related with the static stability in the upper troposphere (Fig. 2f). This result indicates that $\mathrm{COV}$ increases due to a decrease of static stability around the tropopause induced by a cooling in the lower stratosphere associated with the SSW, consistent with the results of Kuang and Bretherton (2004) and Chae and Sherwood (2010). Our previous numerical experiment also shows that, when local

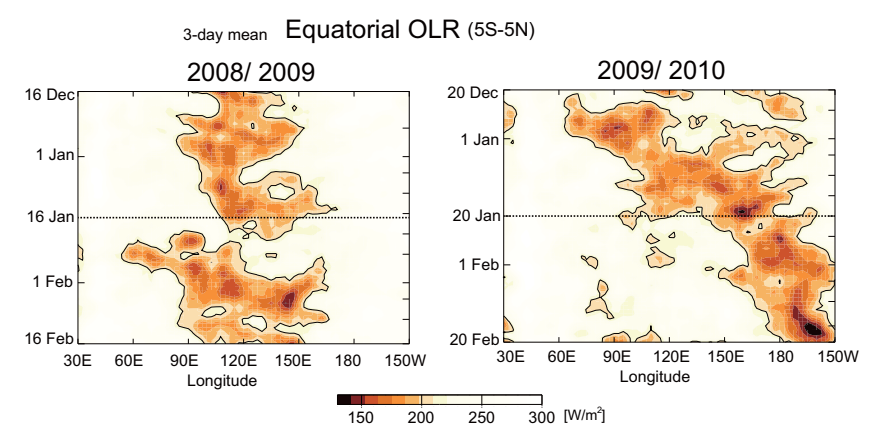

Figure 6. Time-longitude sections of 3-day running mean equatorial $\left(5^{\circ} \mathrm{S}-5^{\circ} \mathrm{N}\right)$ OLR over the Indian Ocean-central Pacific sector $\left(30^{\circ} \mathrm{E}-150^{\circ} \mathrm{W}\right)$ during boreal winter for (left) 2008/2009 and (right) 2009/2010. The figure displays a 2-month period centred on the onset day of the tropical stratospheric upwelling events (16 January 2009 and 20 January 2010) indicated by horizontal solid lines.

cooling occurs near the tropopause, upwelling enhances, accompanying a warming in the lower TTL and the upper troposphere (see Fig. 4 of Kodera et al., 2011a). A global nonhydrostatic model study (Eguchi et al., 2015) also confirmed the relationship suggested in the present result. Therefore, we consider that, although the cooling effect by stratospheric upwelling is limited in the stratosphere, its effect can further penetrate below through changes in COV and deep convective activity.

Changes were also noted in the spatial distribution of the convective activity following the stratospheric event (Fig. 4). When stratospheric upwelling was suppressed before the onset of the event (period i), convection tended to cluster around the equatorial Maritime Continent or western Pacific region depending on the phase of ENSO. When the stratospheric upwelling increased (period ii), convection expanded over a wide range of longitudes in the tropical summer hemisphere. In other words, tropical circulation changed from a more Walker-like (east-west) configuration to more of a Hadley (north-south) type.

The Madden-Julian Oscillation (MJO) (Madden and Julian, 1994) has a significant influence on tropical convective activity. It is reported that the occurrence of the SSW is related with the phase of the MJO (Garfinkel et al., 2012; Liu et al., 2014). One would ask whether or not the present phenomenon is associated with the MJO. The features of the MJO in January 2009 and 2010 differed significantly as can be seen in Fig. 6. A convective centre remained stationary over the Maritime Continent prior to the onset of the 2009 stratospheric event, after which an eastward propagation was initiated from the Indian Ocean. In contrast, an eastwardpropagating convective centre became almost stationary over the western Pacific after the onset in January 2010. In spite of the differences in the MJO in January 2009 and 2010, circulation changes related to the stratospheric events showed sim- 
ilar features during both winters, suggesting that the present phenomenon is independent of the MJO.

The certainty of the dynamical connections identified here is of course limited by the small number and the relatively short duration of the events. Further certainty will come from future modelling studies and observational studies of a larger set of events.

Acknowledgements. We thank R. Ueyama, T. Nasuno, and C. Kodama for useful comments and discussion. This work was supported in part by JSPS Grants-in-Aid for Scientific Research (S)24224011 and (C)25340010. B. M. Funatsu and C. Claud acknowledge the support of DGA (Project PRECIP-CLOUD) and CNES. MHS data are available at NOAA's Comprehensive Large Array Data Stewardship System (Data set: TOVS); in this work, MHS was obtained with support from the INSU-CNES French Mixed Service Unit ICARE via CLIMSERV-IPSL. CALIOP data were from Atmospheric Science Data Center (ASDC) at NASA. TRMM data were acquired through the Giovanni online data system, developed and maintained by NASA GES DISC.

Edited by: P. Haynes

\section{References}

Arkin, P. A. and Ardanuy, P. E.: Estimating climate-scale precipitation from space: A review, J. Climate, 2, 1229-1238, 1989.

Ayarzagüena, B., Langematz, U., and Serrano, E.: Tropospheric forcing of the stratosphere: A comparative study of the two different major stratospheric warmings in 2009 and 2010, J. Geophys. Res., 116, D18114, doi:10.1029/2010JD015023, 2011.

Chae, J.-H. and Sherwood, S. C.: Insights into cloud-top height and dynamics from the seasonal cycle of cloud-top heights observed by MISR in the West Pacific region, J. Atmos. Sci., 67, 248-261, 2010.

Dee, D. P., Uppala, S. M., Simmons, A. J., et al.: The ERA-Interim reanalysis: configuration and performance of the data assimilation system, Q. J. Roy. Meteorol. Soc., 137, 553-597, 2011.

Eguchi, N. and Kodera, K.: Impact of the 2002, Southern Hemisphere, stratospheric warming on the tropical cirrus clouds and convective activity, Geophys. Res. Lett., 34, L05819, doi:10.1029/2006GL028744, 2007.

Eguchi, N. and Kodera, K.: Impacts of stratospheric sudden warming on tropical clouds and moisture fields in the TTL: A case study, SOLA, 6, 137-140, doi:10.2151/sola.2010-035, 2010.

Eguchi, N., Kodera, K., and Nasuno, T.: A global non-hydrostatic model study of a downward coupling through the tropical tropopause layer during a stratospheric sudden warming, Atmos. Chem. Phys., 15, 297-304, doi:10.5194/acp-15-297-2015, 2015.

Fritz, S. and Soules, S. D.: Large-scale temperature changes in the stratosphere observed from Nimbus III, J. Atmos. Sci., 27, 10911097, 1970.

Funatsu, B. M., and Waugh, D. W.: Connections between potential vorticity intrusions and convection in the eastern tropical Pacific, J. Atmos. Sci., 65, 987-1002, 2008.

Funatsu, B. M., Dubreuil, V., Claud, C., Arvor, D., and Gan, M. A.: Convective activity in Mato Grosso state (Brazil) from microwave satellite observations: Comparisons between AMSU and TRMM data sets, J. Geophys. Res., 117, D16109, doi:10.1029/2011JD017259, 2012.

Garfinkel, C. I., Feldstein, S. B., Waugh, D. W., Yoo, C., and Lee, S.: Observed connection between stratospheric sudden warmings and the Madden-Julian Oscillation, Geophys. Res. Lett., 39, L18807, doi:10.1029/2012GL053144, 2012.

Harada, Y., Goto, A., Hasegawa, H., Fujikawa, N., Naoe, H., and Hirooka, T.: A major stratospheric sudden warming event in January 2009, J. Atmos. Sci., 67, 2052-2069, 2010.

Hong, G., Heygster, G., Miao, J., and Kunzi, K.: Detection of tropical deep convective clouds from AMSU-B water vapor channels measurements, J. Geophys. Res., 110, D05205, doi:10.1029/2004JD004949, 2005.

Hong, G., Heygster, G., Notholt, J., and Buehler, S. A.: Interannual to diurnal variations in tropical and subtropical deep convective clouds, J. Clim., 21, 4168-4189, 2008.

Huffman, G. J., Bolvin, D. T., Nelkin, E. J., Wolff, D. B., Adler, R. F., Gu, G., Hong, Y., Bowman, K. P., and Stocker, E. F.: The TRMM Multisatellite Precipitation Analysis (TMPA): Quasiglobal, multiyear, combined-sensor precipitation estimates at fine scales, J. Hydrometeorol., 8, 38-55, 2007.

Kuang, Z. and Bretherton, C. S.: Convective influence on the heat balance of the tropical tropopause layer: A cloud-resolving model study, J. Atmos. Sci., 61, 2919-2927, 2004.

Kiladis, G. N. and Weickmann, K. M.: Extratropical forcing of tropical Pacific convection during northern winter, Mon. Weather Rev., 120, 1924-1939, 1992.

Kodera, K.: Influence of stratospheric sudden warming on the equatorial troposphere, Geophys. Res. Lett., 33, L06804, doi:10.1029/2005GL024510, 2006.

Kodera, K., Mukougawa, H., and Kuroda, Y.: A general circulation model study of the impact of a stratospheric sudden warming event on tropical convection, SOLA, 7, 197-200, doi:10.2151/sola.2011-050, 2011a.

Kodera, K., Eguchi, N., Lee, J.-N., Kuroda, Y., and Yukimoto, S.: Sudden changes in the tropical stratospheric and tropospheric circulation during January 2009, J. Meteor. Soc. Jpn, 89, 283-290, $2011 b$.

Li, Y. and Thompson, D. W. J.: The signature of the stratospheric Brewer-Dobson circulation in tropospheric clouds, J. Geophys. Res., 118, 3486-3494, doi:10.1002/jgrd.50339, 2013.

Liu, C., Tian, B., Li, K.-F., Manney, G. L., Livesey, N. J., Yung, Y. L., and Waliser, D. E.: Northern Hemisphere mid-winter vortex-displacement and vortex-split stratospheric sudden warmings: Influence of the Madden-Julian Oscillation and QuasiBiennial Oscillation, J. Geophys. Res. Atmos., 119, 12599 12620, doi:10.1002/2014JD021876, 2014.

Madden, R. A. and Julian, P. R.: Observations of the 40-50-day tropical oscillation - A review, Mon. Weather Rev., 122, 814837, 1994.

Plumb, R. A. and Eluszkiewicz, J.: The Brewer-Dobson circulation: Dynamics of the tropical upwelling, J. Atmos. Sci., 56, 868-890, 1999.

Randel, W. J., Garcia, R. R., and Wu, F.: Time-dependent upwelling in the tropical lower stratosphere estimated from the zonal-mean momentum budget, J. Atmos. Sci., 59, 2141-2152, 2002. 
Taguchi, M.: Latitudinal extension of cooling and upwelling signals associated with stratospheric sudden warmings, J. Meteorol. Soc. Jap., 89, 571-580, 2011.

Thuburn, J. and Craig, G. C.: Stratospheric influence on tropopause height: the radiative constraint, J. Atmos. Sci., 57, 17-28, 2000.
Ueyama, R., Gerber, E. P., Wallace, J. M., and Frierson, D. M. W.: The role of high-latitude waves in the intraseasonal to seasonal variability of tropical upwelling in the Brewer-Dobson circulation, J. Atmos. Sci., 70, 1631-1648, 2013.

Winker, D. M., Hunt, W. H., and McGill, M. J.: Initial performance assessment of CALIOP, Geophys. Res. Lett., 34, L19803, doi:10.1029/2007GL030135, 2007. 